\title{
AMS100
}

ADVANCING SCIENCE, SERVING SOCIETY SINCE 1919

\section{YOUR COMMUNITY.}

YOUR SOCIETY.

YOUR SUCCESS.

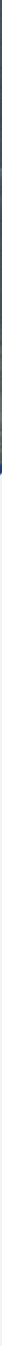

As we continue to celebrate 100 years of advancing the atmospheric, oceanic, and hydrologic sciences and leveraging them for the benefit of society, we encourage you to renew your AMS membership. Stay engaged with the weather, water, and climate community by renewing as a full member-the new tiered dues structure starts at \$35/year.

\section{AMETSOC.ORG/RENEW}

